\title{
Effect of restricted freedom on health in China
}

\author{
Therese Hesketh, Wei Xing Zhu
}

China has shown how a non-democratic system can benefit the health of the population, but can health gains be sustained as the country becomes freer?

China is not free. In fact, according to Freedom House, which was the source of the classification for freedom in the article by Franco et al, China is near the bottom of the freedom index, along with countries such as Saudi Arabia, Uzbekistan, North Korea, and Burma. ${ }^{2}$ Even Iran scores better than China. But China provides probably one of the best examples of how not being free can actually be good for health.

From the 1950 s to the '70s China achieved considerable improvements in the health of its people while being ruled by one of the most authoritarian regimes of the century and while being one of the poorest countries in the world. Many of the most effective public health measures were possible precisely because China was not a democracy. These included the closure of brothels and opium dens, the mobilisation of the population to eliminate the four pests (flies, mosquitoes, rats, and sparrows), and the training of a million barefoot doctors by city doctors sent to the countryside for this purpose. Prevention was explicitly prioritised. The Chinese claimed impressive results: the virtual eradication of sexually transmitted diseases, schistosomiasis, and leprosy; universal access to health care; and the creation of a system of primary health care that was hailed as a model for the rest of the world. ${ }^{3}$ It was estimated that between 1950 and 1965 infant mortality fell from over 200 to 50 per 1000 live births. ${ }^{4}$ External verification of these achievements was limited, however, because China was virtually closed to the outside world at the time.

The irony is that as China has become freer (not reflected by Freedom House's classification) some of the advances in health have been reversed. The market economy, which replaced the centralised one in the early 1980s, has taken over the health sector. Universal access to health care has gone, and for many poor rural Chinese even basic health care has become

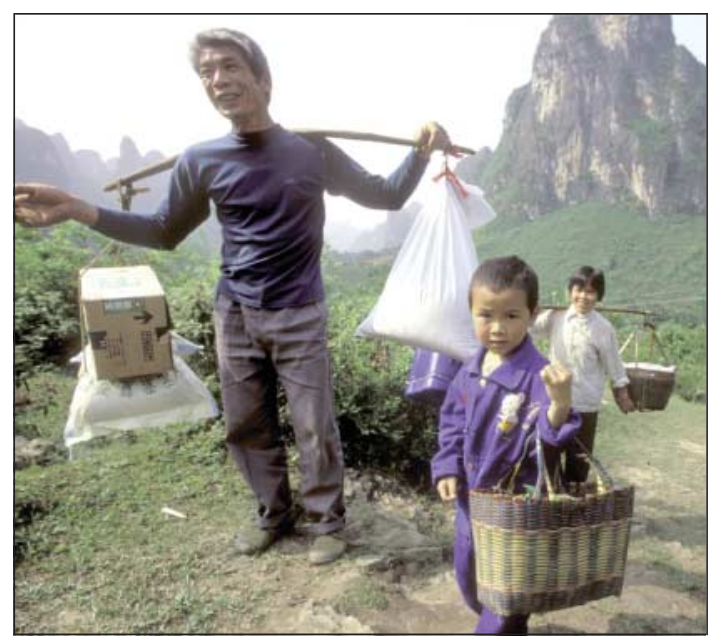

Basic health care is unaffordable for many poor people in rural China

\section{Summary points}

Despite being ruled by an authoritarian regime from the 1950s to '70s, China achieved huge improvements in public health

Some of the benefits are difficult to verify because China was virtually closed during that period

With China's gradual change to a freer political system, some of the advances in health have regressed

China's population constitutes over two thirds of the non-free people of the world and is therefore an important part of any discussions on the effects of politics on health

unaffordable. Moreover, prevention is no longer prioritised. This has been reflected in worsening health indicators in some rural areas. ${ }^{5}$

In 2003, China showed the world how a non-democratic system can be mobilised to the benefit of the public's health when it managed the outbreak of severe acute respiratory syndrome. Although there was a delay in recognising the gravity of the situation, the government reacted with extraordinary speed after the epidemic was publicly known. Within 24 hours strict quarantine measures were in place; bars, restaurants, and clubs were closed and people were screened for raised temperature at airports, bus and train stations, and in schools. Within three months the epidemic was over. Such draconian measures would be almost unthinkable in a democratic system.

China cannot be ignored in the health and democracy equation. Over two thirds of the non-free people in the world live there. ${ }^{1}$ If Franco et al had weighted countries in their model by population size, being not free would almost certainly have proved most beneficial to people's health. What their paper shows most clearly is that income is a far more important influence on health. The political system is a minor influence in comparison-or maybe it's just irrelevant.

Contributors: TH and WXZ wrote the article and are guarantors.

Competing interests: None declared.

1 Freedom House. Freedom in the world country ratings 2003. www.freedomhouse.org (accessed 6 Oct 2004).

Franco A, Alvarez-Dardet, Ruiz MT. Effect of democracy on health: ecological study. BMJ 2004;329:1421-4.

Hesketh T, Zhu WX. Health in China: from Mao to market reform. BMJ 1997;314:1543-5.

Sidel R, Sidel V. The health of China. Boston, MA: Beacon Press, 1982.

5 Cook IG, Dummer T. Changing health in China: re-evaluating the epidemiological transition model. Health Policy 2004;67:329-43.
Institute of Child Health, University College London, London

WC1 N1EH

Therese Hesketh senior lecturer in international child health

Zhejiang Normal University,

Hangzhou 310006, People's Republic of

China

Wei Xing Zhu visiting professor in population health

Correspondence to: T Hesketh thesketh@ich.ucl.ac.uk

BMJ 2004;329:1427 